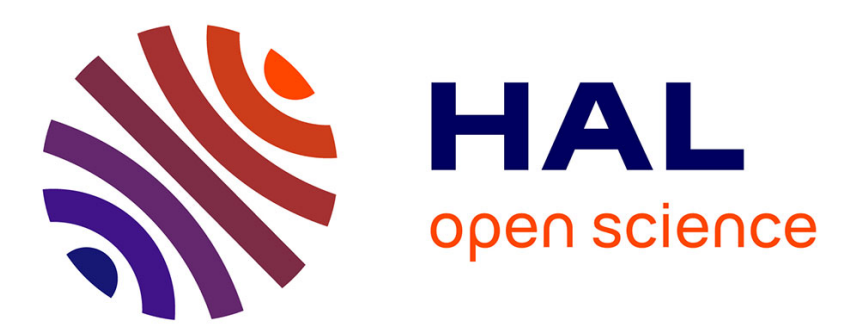

\title{
Dual Requirement for the EcR/USP Nuclear Receptor and the dGATAb Factor in an Ecdysone Response in Drosophila melanogaster
}

Véronique Brodu, Bruno Mugat, Jean-Yves Roignant, Jean-Antoine Lepesant, Christophe Antoniewski

\section{To cite this version:}

Véronique Brodu, Bruno Mugat, Jean-Yves Roignant, Jean-Antoine Lepesant, Christophe Antoniewski. Dual Requirement for the EcR/USP Nuclear Receptor and the dGATAb Factor in an Ecdysone Response in Drosophila melanogaster. Cellular and molecular biology, including cytoenzymology, 1999. hal-03030769

\section{HAL Id: hal-03030769 https://hal.science/hal-03030769}

Submitted on 14 Dec 2020

HAL is a multi-disciplinary open access archive for the deposit and dissemination of scientific research documents, whether they are published or not. The documents may come from teaching and research institutions in France or abroad, or from public or private research centers.
L'archive ouverte pluridisciplinaire HAL, est destinée au dépôt et à la diffusion de documents scientifiques de niveau recherche, publiés ou non, émanant des établissements d'enseignement et de recherche français ou étrangers, des laboratoires publics ou privés. 


\title{
Dual Requirement for the EcR/USP Nuclear Receptor and the dGATAb Factor in an Ecdysone Response in Drosophila melanogaster
}

\author{
VÉRONIQUE BRODU, BRUNO MUGAT, JEAN-YVES ROIGNANT, JEAN-ANTOINE LEPESANT, \\ AND CHRISTOPHE ANTONIEWSKI*
}

\author{
Institut Jacques Monod, Laboratoire de Biologie du Développement, CNRS UMR 7592, \\ Université Paris 7 Denis-Diderot, Université Paris 6 P. et M. Curie, \\ 75251 Paris Cedex 05, France
}

Received 21 April 1999/Returned for modification 6 May 1999/Accepted 20 May 1999

\begin{abstract}
The EcR/USP nuclear receptor controls Drosophila metamorphosis by activating complex cascades of gene transcription in response to pulses of the steroid hormone ecdysone at the end of larval development. Ecdysone release provides a ubiquitous signal for the activation of the receptor, but a number of its target genes are induced in a tissue- and stage-specific manner. Little is known about the molecular mechanisms involved in this developmental modulation of the EcR/USP-mediated pathway. Fbpl is a good model of primary ecdysone response gene expressed in the fat body for addressing this question. We show here that the dGATAb factor binds to three target sites flanking an EcR/USP binding site in a 70-bp enhancer that controls the tissue and stage specificity of $\mathrm{Fbp} 1$ transcription. We demonstrate that one of these sites and proper expression of dGATAb are required for specific activation of the enhancer in the fat body. In addition, we provide further evidence that EcR/USP plays an essential role as a hormonal timer. Our study provides a striking example of the integration of molecular pathways at the level of a tissue-specific hormone response unit.
\end{abstract}

Nuclear receptors for steroid and retinoid hormones are transcription factors that bind to gene promoters, recruit coactivators or corepressors, and modulate the activity of the transcription machinery. A wealth of information concerning these mechanisms has been provided by in vitro approaches or studies with cultured cell systems $(19,30)$. In whole organisms, gene responses to circulating hormones depend on both the target tissue and the developmental stage. Accordingly, nuclear receptor binding sites in natural promoters are often found included in composite assemblages of multiple binding sites for a variety of transcription factors (29). These so-called hormone response units are thought to integrate multiple regulatory pathways responsible for the tissue and time specificity of the transcriptional hormonal response. However, the mechanisms by which this integration occurs in animals are poorly understood.

Drosophila melanogaster provides a choice model for the study of a steroid hormone response in the context of a developing organism. At the end of the third larval instar, a major pulse of 20-hydroxyecdysone (hereafter referred to as ecdysone) triggers the larval-to-prepupal morphological transition and initiates metamorphosis (3). During this period, the ecdysone receptor, a heterodimer between the EcR and USP proteins, two members of the nuclear receptor superfamily $(22,46$, 52 ), orchestrates complex waves of gene transcription in target tissues of ecdysone. The regulatory pathways controlling this genetic program at the temporal level have been examined in detail (see reference 47 for a review; see also references 11, 23, and 50 for recent advances). Despite these advances, how transcription of genes, in response to circulating ecdysone, is

\footnotetext{
* Corresponding author. Mailing address: Institut Jacques Monod, Laboratoire de Biologie du Développement, CNRS UMR 7592, Universités Paris 6 et Paris 7, 2 place Jussieu, 75251 Paris Cedex 05, France. Phone: (33 1) 442778 12. Fax: (33 1) 442752 65. E-mail: antoniewski@ijm.jussieu.fr.
}

restricted to a subset or a single target tissue remains an open question.

We used Fbpl as a model gene to address this question. Fbp1, which encodes a receptor mediating the uptake of hexamerins from the hemolymph (12), is transcribed in response to ecdysone exclusively in the fat body during the second half of the third larval instar $(2,27)$. Germ line transformation analysis of its promoter has pinpointed a 70-bp enhancer $(-69$ to -138 ) sufficient to specify the spatially and temporally ecdysteroid-controlled pattern of Fbp1 expression (24). The EcR/ USP heterodimer binds to a pseudopalindromic site in the 70-bp Fbp1 enhancer (4). Mutations of this site completely abolished the ability of the Fbpl enhancer to confer a fat body-specific ecdysteroid response onto a minimal promoterlacZ reporter transgene, indicating that activation by the EcR/ USP heterodimer is a strict requirement for the activity of the Fbp1 enhancer (5). Germ line transformation experiments showed, however, that an EcR/USP binding site was unable by itself to confer an ecdysteroid response onto the same minimal-promoter-lac $Z$ reporter gene, even when multimerized. This provided evidence that other transcription factors, targeted to sequences flanking the EcR/USP binding site in the Fbp1 enhancer, must act in vivo, in addition to the ecdysone receptor, to mediate an ecdysteroid genetic response (5).

Analysis of the role of these sequences is complicated by the fact that their regulatory function cannot be revealed in the absence of activation by the liganded EcR/USP heterodimer. We show here that replacement of the EcR/USP binding site with an upstream activation sequence (UAS) site can circumvent this limitation. In the presence of the yeast activator GAL4, transcriptional activation of this modified Fbpl enhancer remains restricted to the third-instar fat body, providing direct confirmation that sequences flanking the EcR/USP binding site play an important role in this specific activation. We further show that dGATAb, the product of the serpent (srp) gene, binds in the close vicinity of the EcR/USP binding site 
and is strictly required for activation of the $F b p 1$ enhancer. Together, our results demonstrate that the Fbpl enhancer functions as a complex ecdysone response unit integrating spatial and temporal cues in a specific response to the hormonal signal and provide evidence for the central role played by the EcR/USP nuclear receptor as a developmental timer in this process.

\section{MATERIALS AND METHODS}

Plasmids. A BamHI-DraI fragment from the srp cDNA (a gift from K. P. Rehorn and R. Reuter) was subcloned into the bluescript KS + plasmid between the BamHI and SmaI sites. The resulting construct, pBS-srp, allows coupled in vitro transcription-translation of the Srp protein. For bacterial expression of Srp, we isolated the srp cDNA from pBS-srp as a BamHI-EcoRI fragment and inserted it after Klenow blunting into the SmaI cloning site of the glutathione $S$-transferase (GST)-tagged expression vector pGEX-3X (Pharmacia). The germ line transformation vector pAE was described in reference 5, where it was referred to as pAEP1. pAE[UAS] was derived from pAE by PCR mutagenesis of the ATTCATTCAAC EcR/USP binding site in the Fbp1 enhancer (see Fig. 3). This sequence was replaced with the UAS CGGAGTACTGTCCTCCG in the pAE[UAS] construct. Plasmids $\mathrm{pAE} \alpha, \mathrm{pAE} \beta, \mathrm{pAE} \beta^{\prime}$, and $\mathrm{pAE} \beta \beta^{\prime}$ were derived from pAE by mutagenesis (for the positions used, see Fig. 3). The structures of all of the mutagenized transformation vectors were confirmed by direct sequencing.

GATAb production in bacteria or rabbit reticulocyte lysate. Crude GST-Srp bacterial extract was prepared as described in reference 16 from Escherichia coli BL21 transformed with the pGST-srp expression vector. This extract was purified by glutathione-Sepharose affinity chromatography in accordance with the manufacturer's (Pharmacia) recommendations. The full-length Srp protein was translated in a rabbit reticulocyte lysate by using the pBS-srp plasmid and T7 RNA polymerase in a Promega coupled transcription-translation system.

DNase I footprinting. Oligonucleotides 5' GTAGCGGCCGCATGACAACA ATTTATTTAAT 3' (upper primer) and 5' CTGCAGCTTTTATACCC 3' (lower primer) were used to amplify by PCR a -194 to -18 fragment from the $F b p 1$ promoter. Depending on the DNA strand that was to be analyzed, the upper or lower primer was ${ }^{32} \mathrm{P}$ labelled by using T4 polynucleotide kinase. A 0.2 -pmol sample of the labelled -194 to $-18 \mathrm{Fbp} 1$ fragment was mixed with $1 \mu \mathrm{g}$ of crude bacterial extract or $100 \mathrm{ng}$ of GST-purified GATAb and $2 \mu \mathrm{g}$ of poly(dI-dC) in binding buffer (25 mM HEPES [pH 7.6], $60 \mathrm{mM} \mathrm{KCl,} 5 \%$ glycerol, $5 \mathrm{mM} \mathrm{MgCl}$, $0.1 \mathrm{mM}$ EDTA [pH 8], $0.75 \mathrm{mM}$ dithiothreitol [DTT]) in a final volume of $16 \mu \mathrm{l}$. After $20 \mathrm{~min}$ at $4^{\circ} \mathrm{C}, 3 \mu \mathrm{l}$ of DNase I (Worthington) at $2.6 \mu \mathrm{g} / \mathrm{ml}$ was added and the mixture was left for $2.5 \mathrm{~min}$. The reaction was then stopped by addition of 40 $\mu$ l of stop solution (20 mM EDTA, $0.1 \%$ sodium dodecyl sulfate [SDS]). DNA was phenol-chloroform extracted twice, ethanol precipitated, resuspended in a formamide-dye mixture, and electrophoresed in an $8 \%$ polyacrylamide-urea sequencing gel.

Fat body nuclear extracts. All of the buffers used for nuclear extract preparation were supplemented with protease inhibitors $(0.5 \mathrm{mM}$ Pefablock and aprotinin at $10 \mu \mathrm{g} / \mathrm{ml})$. Late-third-instar larvae were dissected in buffer $\mathrm{C}(20 \mathrm{mM}$ Tris [pH 7.5], $50 \mathrm{mM} \mathrm{KCl,} 2 \mathrm{mM}$ DTT, $0.1 \mathrm{mM}$ EDTA, $0.15 \mathrm{mM}$ spermine, 0.5 $\mathrm{mM}$ spermidine), and fat bodies were immediately frozen in an Eppendorf tube kept on dry ice. When collected, 50 fat bodies were rapidly thawed in $200 \mu \mathrm{l}$ of cold buffer $\mathrm{C}$ and vigorously vortexed. They were then refrozen and thawed twice with vortexing. Nuclei and debris were pelleted upon rapid centrifugation in an Eppendorf centrifuge $(20 \mathrm{~s}$ at $5,500 \times g)$ and washed with $200 \mu \mathrm{l}$ of buffer $\mathrm{C}$. After centrifugation $(15 \mathrm{~s}$ at $5,500 \times g)$, the crude nuclear pellet was suspended in $40 \mu \mathrm{l}$ of extraction buffer $\mathrm{C} 2$ (same as buffer $\mathrm{C}$ but with $600 \mathrm{mM} \mathrm{KCl}$ ) and the homogenate was left on ice for $20 \mathrm{~min}$. After centrifugation $\left(15 \mathrm{~min}\right.$ at $4^{\circ} \mathrm{C}$ and top speed), the supernatant was diluted with 2 volumes of buffer $\mathrm{C} 3$ (same as buffer $\mathrm{C}$ but without $\mathrm{KCl}$ ), aliquoted, and kept at $-80^{\circ} \mathrm{C}$ until use.

Gel shift assays. Three to $4 \mu \mathrm{l}$ of fat body nuclear extract or $3 \mu \mathrm{l}$ of rabbit reticulocyte lysate, $2 \mu \mathrm{g}$ of poly (dI-dC), specific competitor DNA or antibodies, if appropriate, and $2 \mathrm{fmol}$ of ${ }^{32} \mathrm{P}$-labelled probe (about $5 \times 10^{4} \mathrm{cpm} / \mathrm{fmol}$ ) were mixed in binding buffer ( $25 \mathrm{mM}$ HEPES [pH 7], $9 \%$ glycerol, $90 \mathrm{mM} \mathrm{KCl}, 1 \mathrm{mM}$ EDTA [pH 8], $0.9 \mathrm{mM}$ DTT), and gel shift assays were performed as described in reference 4 . Competitions were performed with a 200 -fold molar excess of double-stranded oligonucleotides. Double-stranded oligonucleotides A, A $\alpha, \mathrm{B}$, and $B \beta$ have been described previously (4). The double-stranded oligonucleotide ADH includes the region from -77 to -53 of the D. muleri Adh-1 promoter.

Larval developmental-stage determination. Drosophila stocks were maintained at $25^{\circ} \mathrm{C}$ on a standard Drosophila medium. Developmental-stage determination was carried out essentially as described in reference 2 with a few modifications. Egg laying on a hard agar plate coated with a strip of baker's yeast was restricted to $1 \mathrm{~h}$. Two 1-h precollection egg layings were discarded. Embryos were washed from the yeast, distributed on a hard agar plate, and allowed to develop at $25^{\circ} \mathrm{C}$ until eclosion. First-instar larvae were collected by hand at $1-\mathrm{h}$ intervals, transferred to tubes containing mashed Drosophila medium in batches of 80 larvae, and collected at 6-h intervals from the mid-second larval instar to the late-third larval instar.
RT-PCR. Total RNA (about $100 \mu \mathrm{g}$ ) was isolated from 25 to 50 larvae at different stages as previously described (7), and poly $(\mathrm{A})^{+}$RNA was isolated by using the Oligotex mRNA Midi Kit (Qiagen). Approximately $50 \mathrm{ng}$ of poly(A) ${ }^{+}$ RNA was denatured $\left(65^{\circ} \mathrm{C}\right)$ prior to use as a template in a $20-\mu \mathrm{l}$ cDNA synthesis reaction mixture containing $1 \times$ reverse transcription $(\mathrm{RT})$-PCR buffer $(50 \mathrm{mM}$ $\mathrm{KCl}, 20 \mathrm{mM}$ Tris- $\mathrm{HCl}$ [pH 8.4], $2.5 \mathrm{mM} \mathrm{MgCl}_{2}$, bovine serum albumin at 100 $\mathrm{mg} / \mathrm{ml}, 2.5 \mathrm{mM}$ DTT, $1 \mathrm{mM}$ [each] deoxynucleoside triphosphate), $17.5 \mathrm{U}$ of RNasin (Promega), 100 pmol of random d(N)6 primers, and $8 \mathrm{U}$ of avian myeloblastosis virus reverse transcriptase (Boehringer). The reaction mixture was incubated for $10 \mathrm{~min}$ at $22^{\circ} \mathrm{C}$ and then for $90 \mathrm{~min}$ at $42^{\circ} \mathrm{C}$. One-microliter aliquots of the cDNA reaction mixture were analyzed separately for $\operatorname{srp}$ (38), Fbp1 (31), and the ribosomal protein gene $r p L 17 A$ (34) in 50- $\mu$ l PCR mixtures containing $1 \times$ Taq DNA polymerase buffer (Bioprobe System), $0.2 \mathrm{mM}$ each deoxynucleoside triphosphate, $20 \mathrm{pmol}$ of gene-specific primers, $0.2 \mu \mathrm{l}$ of $\left[{ }^{32} \mathrm{P}\right] \mathrm{dCTP}(3,000 \mathrm{Ci} / \mathrm{mmol}$; Amersham), and $2.5 \mathrm{U}$ of Taq DNA polymerase (Promega). The PCR conditions used were $94^{\circ} \mathrm{C}$ for $3 \mathrm{~min}$ followed by 22 cycles of $94^{\circ} \mathrm{C}$ for $1 \mathrm{~min}, 55^{\circ} \mathrm{C}$ for $1 \mathrm{~min}$, and $72^{\circ} \mathrm{C}$ for $1 \mathrm{~min}$. Control reactions were performed to ensure that the number of amplification cycles was within the logarithmic phase for all three sets of primers (data not shown). All PCR primers were chosen so that they hybridized to separate exons in order to distinguish correctly spliced mRNA from unspliced RNA or contaminating genomic DNA. The srp sense primer was 5' AGCAGCAACAACATCATCAC 3', and the srp antisense primer was $5^{\prime}$ TTGGCAGTCTGAGTAAGCAA 3', corresponding to positions 929 to 948 and 1160 to 1141 , respectively, of the srp cDNA sequence (EMBL nucleotide sequence database accession no. Y07662). The Fbp1 sense primer was 5' ACTACGAATCAGGACAGGGT 3', and the Fbp1 antisense primer was 5' CAGATCGATGACGTTCTGCA 3', corresponding to positions 1552 to 1571 and 1814 to 1795 , respectively, of the $F b p 1$ genomic sequence (EMBL nucleotide sequence database accession no. X69965). The $r p L 17 A$ sense primer was 5' GTGATGAACTGTGCCGACAA 3', and the $r p L 17 A$ antisense primer was $5^{\prime}$ CCTTCATTTCGCCCTTGTTG 3', corresponding to positions 536 to 555 and 1388 to 1369 , respectively, of the $r p L 17 A$ genomic sequence (GenBank nucleotide sequence database accession no. M 85295). Amplification reaction products obtained with $r p L 17 A$ primers were fractionated by electrophoresis on a $6 \%$ polyacrylamide gel and quantified with a Molecular Dynamics PhosphorImager. Amplification reaction products obtained with the srp and Fbp1 primers were then electrophoresed after loading of an amount that was normalized in relation to $r p L 17 A$ amplification.

Antibodies. The \#Srp rabbit antibody was raised against a synthetic peptide corresponding to the 22 last amino acids of GATAb (21). The \#2B8 monoclonal antibody, a generous gift from P. Ramain, was raised against a peptide corresponding to amino acids 378 to 397 of the GATAa/Pannier protein (37). We have shown that this antibody specifically recognizes the TSSSGQA motif that is also present in the N-terminal part of GATAb but is not found in any other known protein (11a). The \#2B8 antibody should thus be considered to be a genuine specific antibody for both GATAa and GATAb.

Antibody staining of tissues. Larvae were dissected in phosphate-buffered saline (PBS), and tissues were fixed for $20 \mathrm{~min}$ at room temperature in $3.4 \%$ paraformaldehyde- $30 \mathrm{mM}$ piperazine- $N, N^{\prime}$-bis(2-ethanesulfonic acid) (PIPES; pH 7.4)-160 mM KCl-40 mM NaCl-4 mM EGTA-1 mM spermidine-0.4 mM spermine- $0.2 \% \beta$-mercaptoethanol- $0.1 \%$ Triton $\mathrm{X}-100$. They were then washed three times with PBT (0.3\% Triton X-100 in PBS) and blocked for $20 \mathrm{~min}$ in PBT that contained $1 \%$ bovine serum albumin. The \#Srp antibody was preabsorbed for $1 \mathrm{~h}$ with dechorionated embryos, diluted 1,000-fold in PBT, and incubated with the tissues overnight at $4^{\circ} \mathrm{C}$. Tissues were washed three times for $20 \mathrm{~min}$ each with PBT and incubated for $1 \mathrm{~h}$ at room temperature with goat anti-rabbit horseradish peroxidase-conjugated secondary antibodies (Vector Laboratories) diluted 400-fold in PBT. The tissues were washed three times for $20 \mathrm{~min}$ each with PBS, and peroxidase activity was detected with PBS supplemented with diaminobenzidine (Sigma) at $0.5 \mathrm{mg} / \mathrm{ml}$ and $0.03 \% \mathrm{H}_{2} \mathrm{O}_{2}$. The reaction was allowed to proceed for $10 \mathrm{~min}$. Tissues were then washed with PBS and mounted on slides in glycerol and photographed.

Western analysis. Samples for developmental Western blotting were prepared by solubilizing fat bodies dissected from 10 to 20 larvae at different stages in 20 $\mu \mathrm{l}$ of cracking buffer $(0.125 \mathrm{M}$ Tris [pH 6.8], $5 \%$-mercaptoethanol, $2 \%$ SDS, 4 $\mathrm{M}$ urea). Samples were electrophoresed on an SDS- $8 \%$ polyacrylamide gel and transferred to nitrocellulose membrane (Schleicher and Schuell) with a Novablot Electrophoretic Transfer Kit (LKB). All subsequent steps were performed at room temperature. The membrane was blocked in milk solution (PBS supplemented with $5 \%$ dry milk and $0.1 \%$ Tween 20 ) for $1 \mathrm{~h}$. \#Srp antibody was diluted 1:10,000 in milk solution and incubated with the membrane for $1 \mathrm{~h}$. The membrane was washed three times for 5 min each with milk solution and incubated for $1 \mathrm{~h}$ with goat anti-rabbit horseradish peroxidase-conjugated secondary antibodies (Vector Laboratories) diluted 1,600-fold in milk solution. The membrane was then washed three times for 5 min each in PBS supplemented with $0.1 \%$ Tween 20, and chemiluminescence detection was performed with the ECL kit (Amersham) in accordance with the manufacturer's instructions. The quantity of protein loaded was estimated by reincubation of the membrane for $1 \mathrm{~h}$ with anti-myosin antibody (53) diluted 1:5,000 in milk solution and chemiluminescence detection as described above.

Germ line transformations, EcR/USP-to-GAL4 substitution, and GATAb overexpression. DNAs of the germ line transformation vector $(250 \mu \mathrm{g} / \mathrm{ml})$ and 
helper plasmid $\Delta 2-3(50 \mu \mathrm{g} / \mathrm{ml})$ were microinjected into embryos of the w1118 recipient stock (40). The $\mathrm{w}^{+}$transformants were screened for eye color. The number of transgenes in each line was determined by Southern blotting.

The GAL4-UAS system (10) was used to study the effects of GAL4-to-EcR/ USP substitution and GATAb overexpression. The effect of GAL4-to-EcR/USP substitution was tested by crossing a line homozygous for the AE[UAS] transgene with the homozygous GAL4 ${ }^{\mathrm{daG} 32}$ line expressing GAL4 under the control of the $d a$ promoter (51). Ubiquitous expression of the $d a$-GAL4 transgene was checked by crossing the GAL4 ${ }^{\mathrm{daG} 32}$ line with a line transgenic for the pUAST construct in which the lac $Z$ reporter gene is under the control of the hsp70 promoter and five UAS sites (10).

For the assay of GATAb overexpression by Western blotting, a line homozygous for an $h s p 70$-GAL4 transgene (third chromosome, line 1799 from Andrea Brand, Bloomington Stock Center) was crossed with a line homozygous for a 5UAS-srp transgene (second chromosome, kindly provided by R. Reuter). Heterozygous larvae obtained from this cross were raised at $25^{\circ} \mathrm{C}$, submitted to a $37^{\circ} \mathrm{C}$ heat shock for $1 \mathrm{~h}$, and allowed to recover for an additional $7 \mathrm{~h}$ at $25^{\circ} \mathrm{C}$. Tissues were then dissected and treated for Western blot analysis. For testing of the effect of overexpression of GATAb on the activity of the Fbp1 promoter, a double homozygous line for the AE transgene (5) and the UAS-srp transgene was constructed by genetic crosses. Larvae obtained from the crossing of this line with the line homozygous for the $h s p 70$-GAL4 transgene were raised at $25^{\circ} \mathrm{C}$ and submitted to a $37^{\circ} \mathrm{C}$ heat shock for $1 \mathrm{~h}$ at various times during the second or third larval instar. Larvae were then allowed to recover for $7 \mathrm{~h}$ at $25^{\circ} \mathrm{C}$, and $\beta$-galactosidase activity was determined by either 5-bromo-4-chloro-3-indolyl- $\beta$-D-galactopyranoside (X-Gal) staining of tissues or quantitative dosage on crude extracts.

Histochemical and spectrophotometric assays of $\beta$-galactosidase activity. A histochemical staining assay of $\beta$-galactosidase activity was performed as previously described (6) by using X-Gal.

A chlorophenol red- $\beta$-D-galactopyranoside (CPRG) spectrophotometric assay of $\beta$-galactosidase activity was performed essentially as previously described (14, 43). At least five protein extracts, each prepared from three larvae, were assayed for each developmental stage. Larvae at different developmental stages were homogenized in $250 \mu \mathrm{l}$ of buffer $(50 \mathrm{mM}$ potassium phosphate [pH 7.5], $1 \mathrm{mM}$ $\mathrm{MgCl}_{2}, 1 \mathrm{mM}$ phenylmethylsulfonyl fluoride) in a 1.5-ml Eppendorf tube and centrifuged at $12,000 \times g$ for $15 \mathrm{~min}$ at $4^{\circ} \mathrm{C}$. The supernatant was transferred to a new Eppendorf tube. Extract (4 to $100 \mu \mathrm{l}$, depending on activity) was added to a 1-ml final volume of assay buffer with CPRG at $0.8 \mathrm{mg} / \mathrm{ml}$ in a disposable cuvette, mixed, and incubated at room temperature. $A_{574}$ was recorded for $1 \mathrm{~h}$ at 10 -min intervals. Activity was calculated by dividing the slope of the assay curve by the amount of protein added for dosage (as determined by Bio-Rad protein assay of the extract). Results are expressed as the mean value of five independent protein extract activities divided by an arbitrary constant for the convenience of data reading.

\section{RESULTS}

GAL4 can substitute for EcR/USP in the tissue-specific activation of the $\boldsymbol{F b p} \mathbf{I}$ promoter. In a previous study (5), we showed that when the Fbp1 enhancer (sequences between positions -194 and -68 ) was fused to the Fbp1 minimal promoter and the lac $Z$ reporter gene, expression of the resulting AE construct (Fig. 1) took place exclusively in the late-third instar larval fat body (Fig. 2A, part A). $\beta$-Galactosidase activity was first detected in 106-h-old larvae and reached a maximum at puparium formation (Fig. 2B). This pattern faithfully reproduced the transcriptional response of the endogenous Fbp1 gene to the major third-instar ecdysone pulse, as shown in earlier studies (2) and in an RT-PCR assay (see Fig. 4A). Replacement of the EcR/USP binding site with a UAS site (Fig. 1) resulted in complete inactivation of the AE[UAS] mutated construct (Fig. 2A, part C), confirming that binding of the EcR/USP receptor is strictly required for in vivo activity of the Fbp1 enhancer. Activation of the AE[UAS] construct by GAL4 was further tested by using the GAL4 ${ }^{\text {daG32 }}$ driver in which a GAL4 cDNA is expressed in all tissues throughout development from the ubiquitous daughterless promoter, as shown in a control cross with a 5UAS-hsp70-lacZ construct (Fig. 2A, part B). When the GAL4 ${ }^{\mathrm{daG} 32}$ construct was crossed in three independent AE[UAS] transgenic lines, $\beta$-galactosidase activity was restored exclusively in the fat bodies of thirdinstar larvae (Fig. 2A, part D). Remarkably, the timing of GAL4-driven expression of the AE[UAS] transgene differed significantly from that of the AE transgene. Expression was first detected in 72-h-old larvae, after the second-to-third-in-

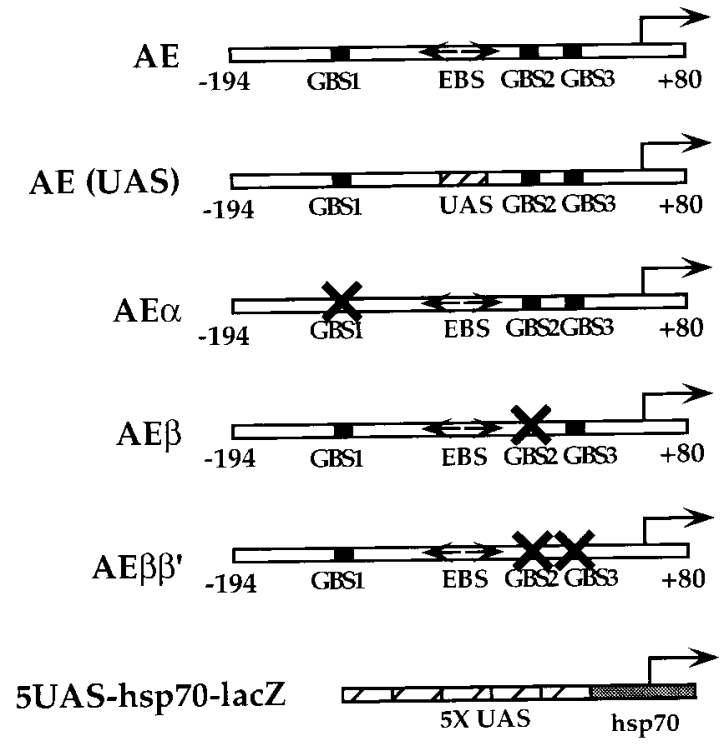

FIG. 1. Structures of lac Z reporter transgenes. Fbpl sequences between -194 and +80 , including the $-138 /-69$ enhancer, were fused to the $l a c Z$ reporter gene, giving rise to the AE reporter construct. Replacement of the EcR/ USP binding site (EBS) with the UAS site gave rise to the AE(UAS) construct. The $\mathrm{AE} \alpha, \mathrm{AE} \beta$, and $\mathrm{AE} \beta \beta^{\prime}$ constructs are mutated at the indicated GATA sites. The 5UAS-hsp70-lac Z construct consists of five multimerized UAS sites fused to the minimal $h s p 70$ promoter and the lac $Z$ reporter gene.

star molt, and subsequently increased gradually throughout the third larval instar (Fig. 2B, black bars). The possibility could be excluded that this dynamic profile of expression was due to variations in the GAL4 level because expression of the 5UAShsp70-lacZ control construct remained constant throughout the third instar in the same $d a$-GAL4 context (Fig. 2B, open bars).

Two conclusions can be drawn from these results. First, they demonstrated that a heterologous transactivator can substitute in vivo for the liganded EcR/USP heterodimer and activate the Fbp1 enhancer. Second, the sequences flanking the EcR/USP binding site are very probably targets for transcription factors that modulate in a tissue-specific manner the activity of an adjacent transactivator, whether the ecdysone receptor is in a natural situation or GAL4 bound to its target site. Under this hypothesis, the activity of these transactivating factors would be acquired gradually during the third larval instar.

An essential GATA binding site is required for enhancer activation. Examination of the Fbpl enhancer sequence revealed the presence of three putative binding sites for the GATA family of transcription factors, hereafter referred to as GATA binding site 1 (GBS1), GBS2, and GBS3 (Fig. 3). The individual requirement of these sites for the activity of the enhancer was tested by mutagenesis of GBS1, GBS2, or both GBS2 and GBS3 in the AE construct (Fig. 1). Mutation of GBS1 completely abolished the ability of the Fbp1 enhancer to drive lac $Z$ expression in third-instar larvae, as tested by X-Gal staining of dissected tissues and quantitative assay of $\beta$-galactosidase activity in a crude larval extract (Fig. 2A, part E; data not shown). In contrast, neither mutation of GBS2 nor double mutation of GBS2 and GBS3 had a significant effect on lac $Z$ expression (Fig. 2A, part F and G). These results indicated that only GBS1 is crucial for the enhancer activity in animals and prompted us to identify the factor involved.

Pattern of expression of GATAb/Serpent in third-instar larvae. dGATAb/Serpent, a member of the GATA family, plays 
A

$\frac{\mathrm{AE}}{\mathrm{AE}}$

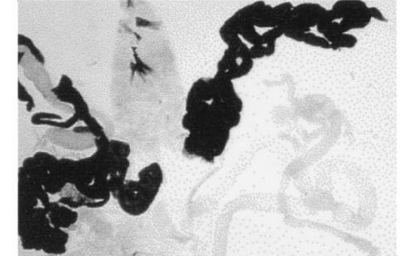

5UAS-hsp70

$\mathbf{A}$

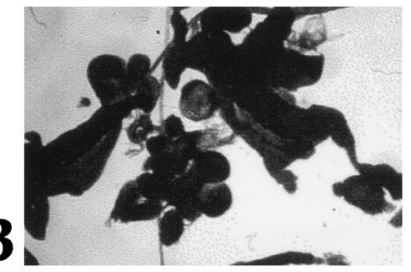

$\frac{\text { AE [UAS] }}{t}$

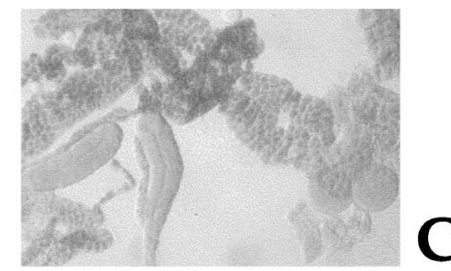
GAL4 ${ }^{\text {daG32 }}$

B

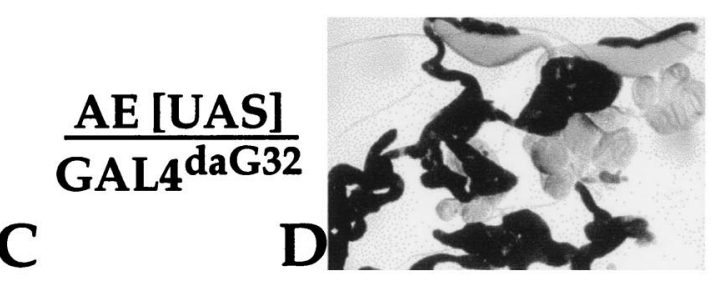

$\frac{\mathrm{AE} \alpha}{\mathrm{AE} \alpha}$

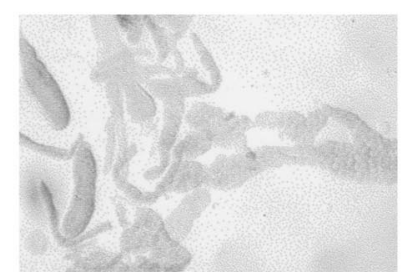

$\mathbf{E}$

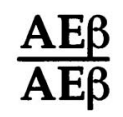

E

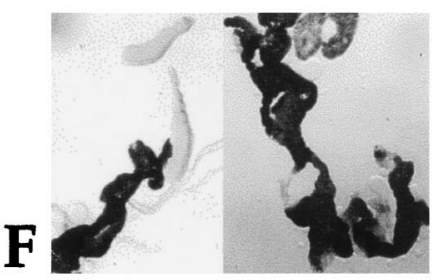

$\underline{A E \beta \beta^{\prime}}$

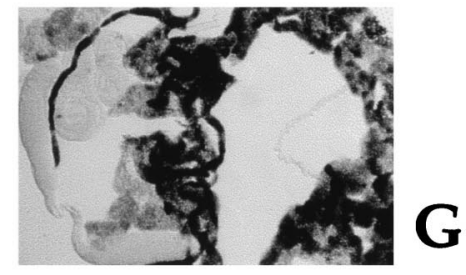

B

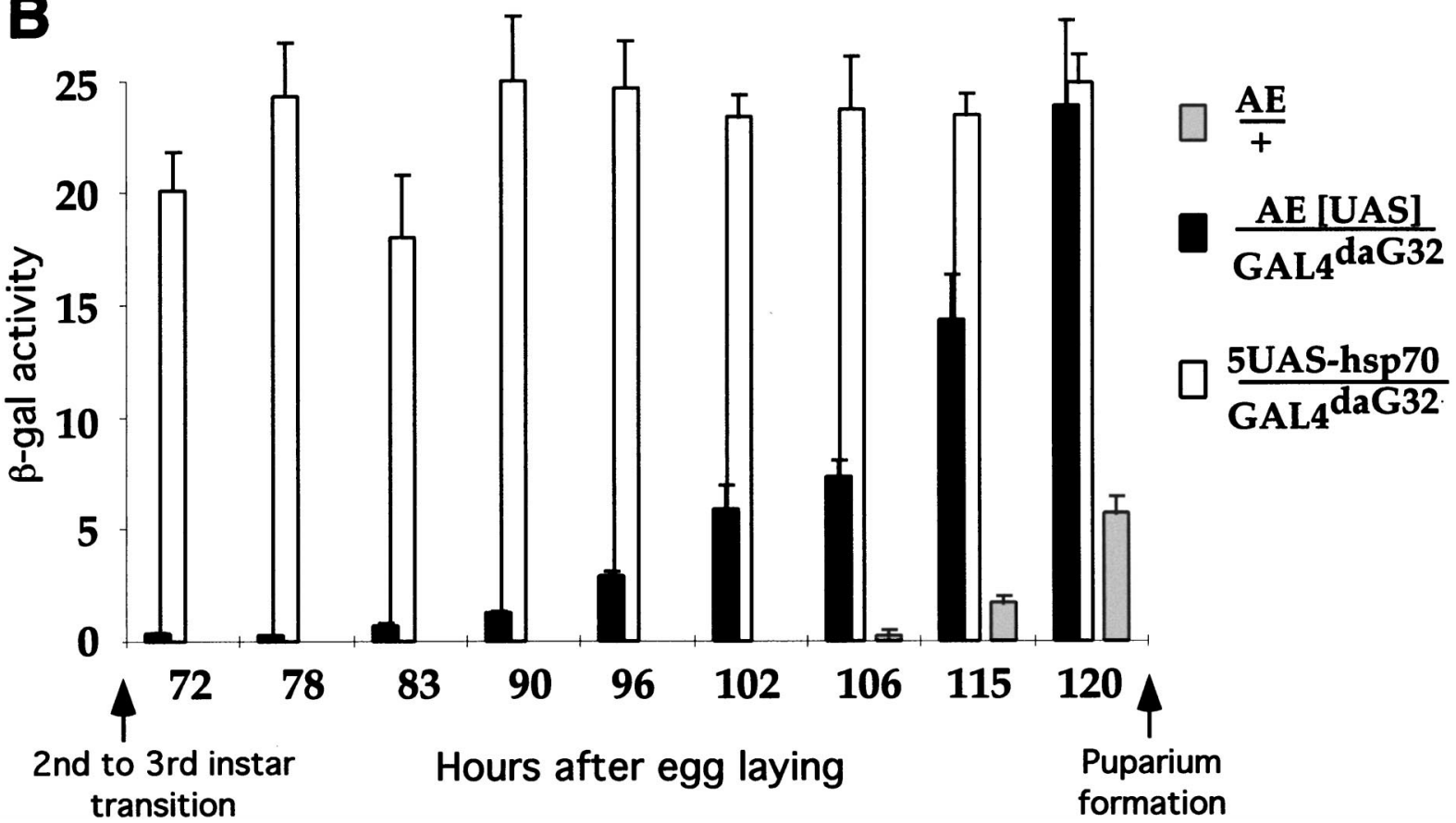

FIG. 2. Pattern of expression conferred by the wild-type or mutated Fbpl enhancers on the lac Z reporter transgene. (A) Late-third-instar larval tissues from transgenic lines with the indicated genotypes were dissected and histochemically stained for determination of $\beta$-galactosidase activity. (B) Transgenic larvae with the indicated genotypes were synchronized at eclosion and recovered during the third larval instar at the indicated times. $\beta$-Galactosidase activity was measured in extracts from whole larvae. Error bars represent the standard error of the mean. 


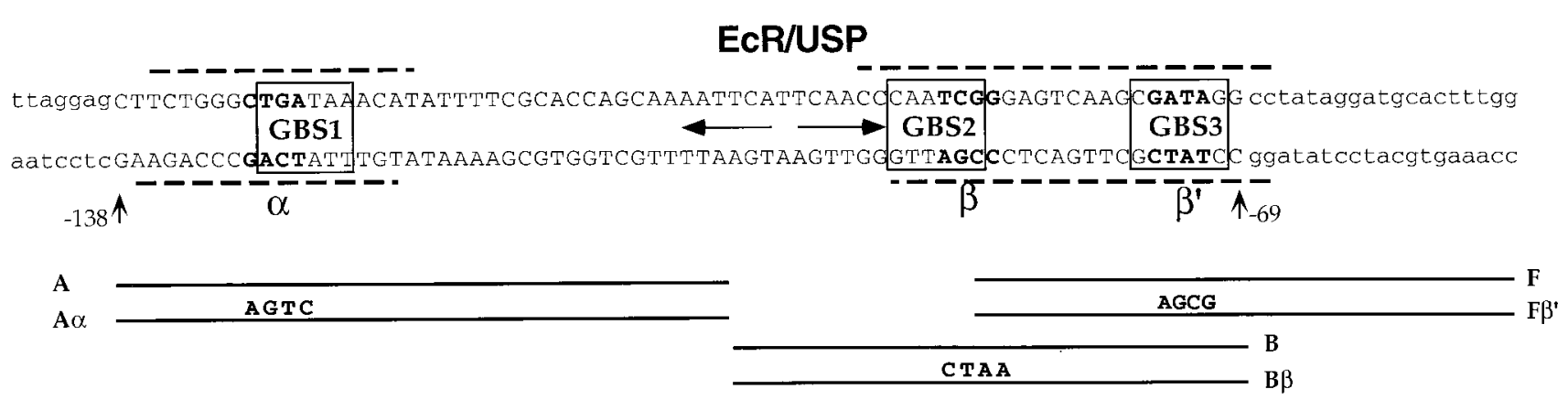

FIG. 3. Structure of the $F b p 1$ enhancer. The sequence of the $F b p 1$ enhancer between positions -138 and -69 relative to the $F b p 1$ transcription start site is in capital letters. Three GATAb binding sites (boxed; GBS1 to GBS3) were found in sequences flanking the pseudopalindromic EcR/USP binding site (horizontal arrows). GBS1 perfectly fits the (A/T)GATA(A/G) consensus sequence for a GBS (18). GBS2 (as read on the lower strand) and GBS3 do not fit this consensus but are efficient binding sites for vertebrate GATA transcription factors (32). Dashed lines indicate the extent of the GATAb footprints (see Fig. 5A) on both DNA strands. The positions and lengths of the competitor oligonucleotides used in gel shift assays are indicated in the lower part of the scheme. Positions of mutations $\alpha, \beta$, and $\beta^{\prime}$ are marked by bold lettering in the Fbp1 enhancer, and sequence substitutions are indicated for each mutated competitor, $\mathrm{A} \alpha, \mathrm{B} \beta$, or $\mathrm{F} \beta^{\prime}$.

an essential role in the development of fat body, endodermal gut, and hematopoietic tissues during embryogenesis $(1,33,38$, $39,41)$. dGATAb was also found to be expressed during the third larval instar and involved in the transcriptional regulation of the D. muleri and D. melanogaster Adh genes in the fat body tissue (1). These data prompted us to consider GATAb as a candidate for the role of a transcription factor that interacts with the Fbp1 regulatory sequences and to establish its tissue and temporal pattern of expression during larval stages.

Using a quantitative RT-PCR assay, we detected a constant level of GATAb mRNA in late-second-instar larvae and throughout the third-instar larval stage (Fig. 4A). Immunostaining using the \#Srp anti-GATAb antibody (21) showed that GATAb was detectable in the nuclei of fat body, gonad, gut, lymph gland, and pericardial cells of late-third-instar larvae (Fig. 4B). We detected no staining in other tissues, such as the central nervous system, imaginal discs, or salivary glands. In a Western blot assay using the \#Srp antibody, the GATAb protein was revealed in the fat body tissue as a double band (Fig. 4C, left side) whose intensity was constant throughout the third larval instar (Fig. 4C, right side). This doublet migrated with a much lower mobility than the $102-\mathrm{kDa}$ molecular mass predicted from the sequence of the GATAb cDNA (38). A confirmation that this doublet corresponded to GATAb isoforms was provided by the detection with the \#Srp antibody of an overexpressed product migrating at the same position after heat shock induction of a UAS-GATAb cDNA construct in an $h s$-GAL4 transgenic line (Fig. 4C, left side; data not shown).

GATAb binds in vitro to the Fbp1 enhancer. Bacterially produced GST-GATAb protein, either in a crude extract or affinity purified, protected two regions of the $F b p 1$ enhancer in a DNase I footprint assay (Fig. 5A). One 17-bp region extended over the GBS1 site from -136 to -120 on the upper strand and from -137 to -121 on the lower strand. A second, larger region included tandemly arranged GBS2 and GBS3 and extended from -92 to -67 on the upper strand and from -90 to -67 on the lower strand.

Binding of in vitro-translated GATAb to a labelled ADH probe previously shown to contain an efficient TGATAA GATAb target site identical to GBS1 (1) gave rise to the formation of a single retarded complex in a gel shift assay (Fig. $5 \mathrm{~B}$, lane 4). This complex was supershifted in the presence of the \#Srp antibody (lane 3) or the \#2B8 antibody (lane 2), which recognizes both the GATAb/Serpent and GATAa/Pannier proteins (see Materials and Methods). The relative binding affinity of in vitro-translated GATAb for GBS1, GBS2, and
GBS3 was further analyzed by competition with unlabelled oligonucleotides corresponding to various subregions (Fig. 3) of the Fbp1 enhancer. Competition in the presence of oligonucleotide A was as efficient as that in the presence of the unlabelled $\mathrm{ADH}$ probe (Fig. 5B, lanes 5 and 6). As expected, this competition was relieved by using the A $\alpha$ oligonucleotide (lane 7) carrying a mutation destroying GBS1 (Fig. 3). Oligonucleotide B or F also competed, although to a lesser extent, for the formation of the GATAb retarded complex (compare lanes 8 and 10 with lanes 5 and 6). These competitions were fully relieved in the presence of oligonucleotides $\mathrm{B} \beta$ and $\mathrm{F} \beta^{\prime}$ carrying mutations destroying GBS2 and GBS3, respectively (lanes 9 and 11). Taken together, these results indicate that GATAb binds with higher affinity to GBS1 than to GBS2 or GBS3.

The GATAb protein in third-instar fat body nuclear extracts binds to the Fbp1 enhancer. When used as a radioactive probe with nuclear extracts from hand-dissected third-instar larval fat bodies, the $F b p 1$ enhancer gave rise to the formation of three complexes a, b, and c (Fig. 6A, lanes 1 and 4), that were supershifted in the presence of the \#2B8 monoclonal antibody alone (Fig. 6A, lane 2) and further supershifted in the presence of \#2B8 and protein A (Fig. 6A, lane 3). The \#2B8 monoclonal antibody recognizes similar epitopes in the GATAa/Pannier and GATAb/Serpent proteins. However, because GATAa/ Pannier expression is undetectable in a third-instar larval fat body (3a), we concluded that all three complexes, a, b, and c, involve the GATAb protein.

GBS1-containing oligonucleotide A (Fig. 6B, lane 1) and, to a lesser extent, GBS3-containing oligonucleotide F (Fig. 6B, lane 2) also gave rise to the formation of complexes a, b, and c. This indicated that GBS1 and GBS3 are involved independently in the formation of complexes a, b, and c. In contrast, GBS2-containing oligonucleotide $\mathrm{B}$ gave rise to the formation of only one retarded complex, c (Fig. 6B, lane 3). As expected, these complexes were supershifted by the \#2B8 antibody and were not formed with any of the GBS-mutated probes, $A \alpha, B \beta$, or $\mathrm{F} \beta^{\prime}$ (data not shown).

Two lines of evidence excluded the possibility that the formation of distinct GATAb-containing complexes resulted from homodimerization, as suggested by examples of GATA family members binding to DNA as homodimers (15). First, we were unable to detect more than one GATAb retarded complex in gel shift assays using in vitro-translated (Fig. 5B) or bacterially produced (not shown) GATAb. Second, a fat body nuclear extract prepared from third-instar larvae overexpressing GATAb gave rise to a predominant retarded band that mi- 
A 2nd 3rd

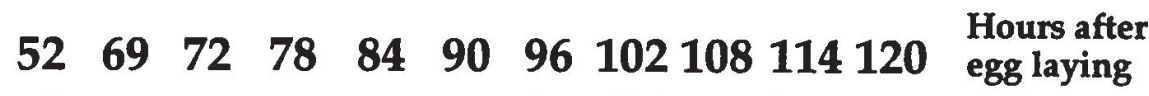

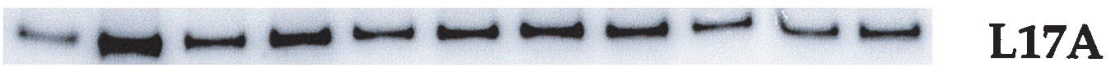 - $-\infty-\infty$ Fbp1 ---------6 GATAb}

B
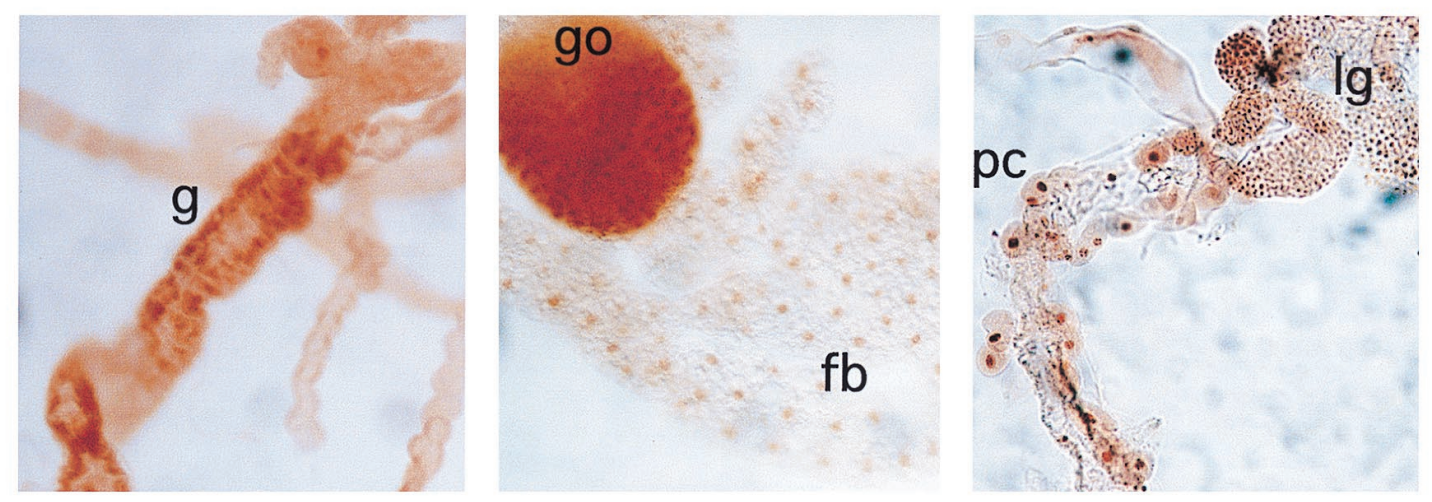

C
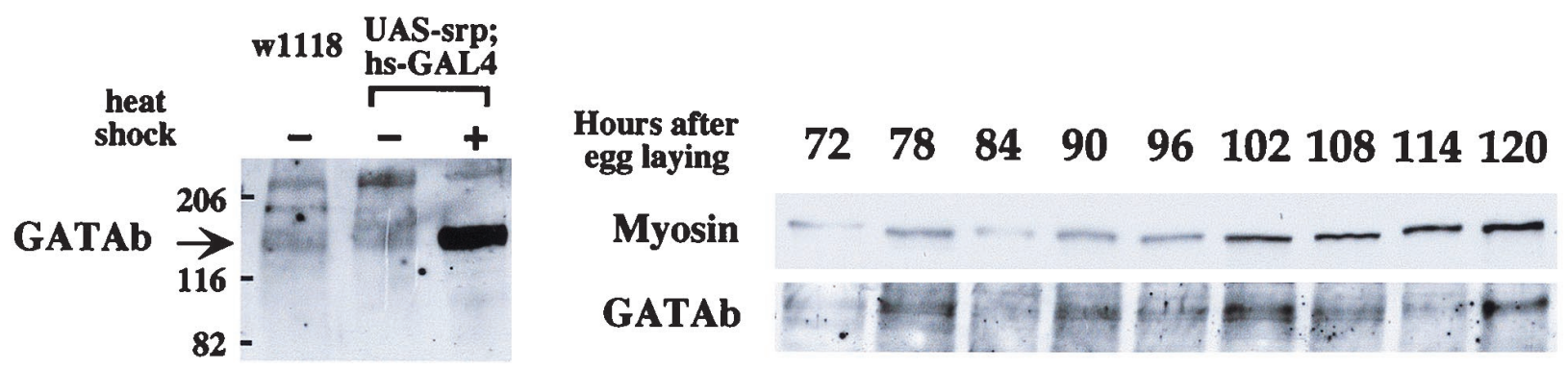

FIG. 4. Expression of GATAb in third-instar larvae. (A) RT-PCR analysis. Total expression of mRNAs for GATAb, Fbp1, and the ribosomal protein L17A was analyzed at specific developmental stages by quantitative RT-PCR using specific primers. (B) Distribution of GATAb in late-third-instar tissues. Tissues were dissected from late-third-instar larvae and stained with the \#Srp anti-GATAb antibody. Nuclear staining was detected in the gut (g), lymph glands (lg), pericardial cells (pc), gonads (go), and fat body (fb). No staining was detected in the other tissues (not shown). (C) Western blot analysis. GATAb-specific bands were identified with the \#Srp antibody in a Western blot analysis by comparing the profiles obtained with fat bodies from w1118 or UAS-srp/hs-GAL4 larvae at $25^{\circ} \mathrm{C}$ with those obtained with fat bodies from UAS-srp/hs-GAL4 larvae after a 1-h heat shock at $37^{\circ} \mathrm{C}$ (left). On the right is the temporal profile of GATAb protein expression in isolated fat bodies as detected by Western blotting. The protein quantity loaded in each lane was estimated by detection of myosin. The values on the left are molecular sizes in kilodaltons.

grated with the same mobility as complex c (Fig. 6A, lane 5). This retardation pattern suggested that complex $\mathrm{c}$ resulted from the binding to DNA of the GATAb protein alone. If complex a or b corresponded to homodimerization or multimerization of GATAb, its intensity would have been reinforced like that of complex c.

Together, these data demonstrated that GATAb was in- volved in the differential formation of distinct complexes on GBS1, GBS2, and GBS3 in a site-specific manner.

GATAb is involved in the timing and tissue specificity of Fbp1 enhancer activation. The effect of total or partial loss of function of GATAb on the activity of the enhancer during the third larval instar could not be studied because all of the GATAb mutations isolated to date are lethal to embryos (38). 


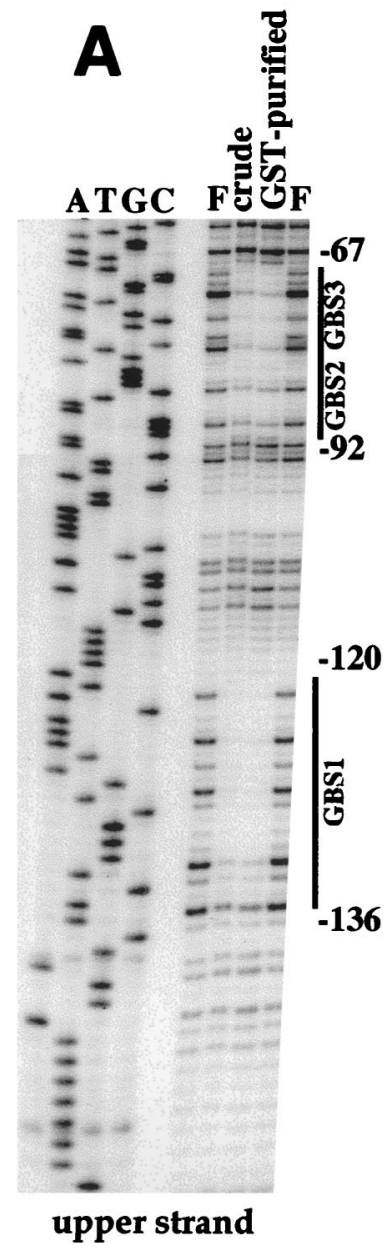

We tested the effect on the AE construct of ubiquitous overexpression of GATAb in triple transgenic AE/hs-GAL4/ UAS-srp larvae. After heat shock at various times during the second or third larval instar followed by a 7-h recovery period, tissues were stained for lac $Z$ expression (Fig. 7A) and the level of $\beta$-galactosidase activity was measured in crude extracts (Fig. $7 \mathrm{~B}$, black bars). As expected, in the absence of heat shock, the $\mathrm{AE}$ reporter transgene was specifically expressed in the fat body at the end of the third larval instar (Fig. 7A, top).

Quantitative measurement indicated that this expression was detectable $108 \mathrm{~h}$ after egg laying and reached a maximum $10 \mathrm{~h}$ later, at puparium formation (Fig. 7B, open bars). In contrast, heat shock treatment resulted in premature induction, as early as the second larval instar, of the AE reporter transgene in the fat body (Fig. 7B). It was also ectopically induced in the salivary glands and proventriculus (Fig. 7A, bottom). That this deregulation was due to the overexpression of GATAb was confirmed by the fact that the spatial and temporal patterns of expression of the $\mathrm{AE}$ transgene were unchanged in a heat-shocked AE/hs-GAL4 control line (data not shown).

We concluded that a proper level of GATAb is crucial for both the correct timing and tissue specificity of Fbp1 expression. However, quantitative dosage of $\beta$-galactosidase activity showed that the magnitude of the effect of GATAb overexpression varies during development. The significant but limited level of AE expression detected during the second larval instar and at the beginning of the third (Fig. 7B) markedly increased between 78 and $108 \mathrm{~h}$ after egg laying. At $108 \mathrm{~h}$ after egg laying, this level was about 10 times that in the absence of heat shock. It was only at the end of the third larval instar (118 h) that the level of AE expression in the absence of heat shock reached a value similar to that in the presence of overexpressed GATAb. These results suggested that the transcriptional response elicited by the increased amount of GATAb was restricted at earlier stages by the availability of additional factors until the end of the third larval instar. The ecdysone receptor possesses all of the features of such a factor.

Both GATAb and the ecdysone receptor are limiting factors in Fbp1 induction. Two factors are known to limit the availability of the active EcR/USP receptor during the third larval instar. First, the expression of the $E c R$ gene increases during the second half of the third larval instar (2). In addition, the activity of the EcR/USP heterodimer is triggered by ecdysteroids, whose concentration peaks during this period of development. We reasoned that if the effect of GATAb overexpression on the AE transgene was limited by the level of active ecdysone receptor, then this dependence should be eliminated in the case of the GAL4-activated AE[UAS] transgene, in which the EcR/USP binding site had been replaced with a UAS site (Fig. 1).

FIG. 5. Bacterially produced or in vitro-translated GATAb binds to the Fbp 1 enhancer. (A) An Fbp 1 promoter fragment 5' end labelled on the upper or lower strand as indicated was incubated in the absence (lane F) or in the presence of a GST-GATAb fusion protein in crude bacterial extract (lane crude) or after GST purification (lane GST-purified). Samples were then treated with DNase I and analyzed on a sequencing gel. Sequencing reactions (lanes A, T, G, and C) performed with the free probe were run in parallel in order to locate GATAbspecific footprints (black lines). Nucleotide positions are shown on the right. (B) A gel shift assay was performed with the labelled double-stranded oligonucleotide $\mathrm{ADH}$ as a probe in the presence of unprogrammed rabbit reticulocyte lysate (lane 1, UL) or in vitro-translated GATAb protein (lanes 2 to 11). A 200-fold molar excess of competitor oligonucleotides or anti-GATAb antibodies was added as indicated (Fig. 3 shows the positions and sequences of the competitors used). 
A

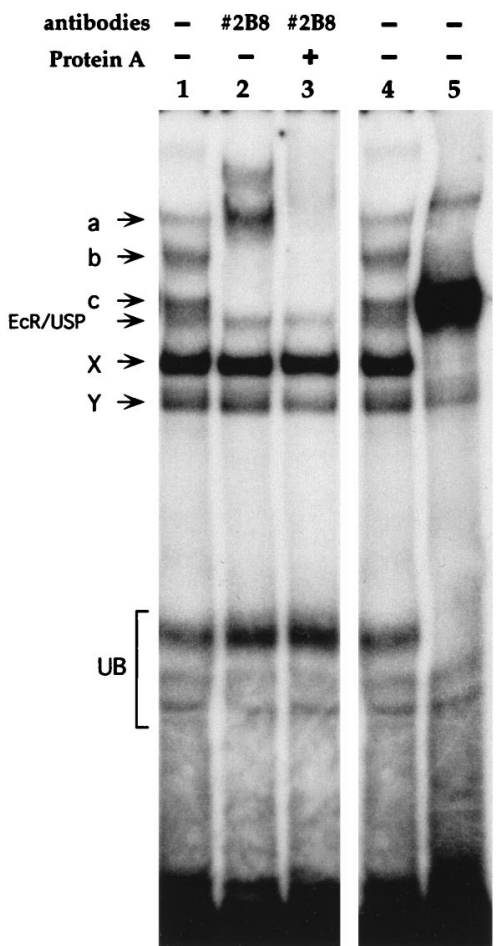

FIG. 6. GATAb in third-instar fat body nuclear extracts binds to the Fbp1 enhancer. (A) Binding of proteins in a nuclear extract from a late-instar fat body was analyzed by a gel shift assay using the $F b p 1$ enhancer $(-138 /-69)$ as a probe, in the presence or absence of $2 \mathrm{~B} 8$ antibody and protein $\mathrm{A}$, as indicated. The EcR/USP complex and faster-migrating complexes $\mathrm{X}$ and $\mathrm{Y}$, whose identities remain unknown, have been characterized previously by using mass-prepared fat body nuclear extracts (4). Control experiments indicated that protein A alone has no effect on the retardation pattern (not shown). The nuclear extract used in lane 5 was prepared from heat-shocked $h s$-GAL4/5UAS-srp transgenic third-instar larvae overexpressing GATAb. Complexes a and b, as well as complexes X, Y, and EcR/USP, were markedly decreased or absent from the retardation pattern obtained with this extract, indicating that expression or stability of the factors responsible for their formation was reduced upon heat shock. Both the major retarded band and the upper minor band were supershifted with the \#2B8 antibody (not shown). This minor band may correspond to the formation of GATAb dimers under conditions of high GATAb concentrations. UB, unspecific binding. (B) Oligonucleotides A, B, and F were used as radioactive probes in a gel shift assay with fat body nuclear extract. Free probes were run out from the gel.

To test this hypothesis, expression of AE[UAS] was analyzed after heat shock-induced expression of GAL4 in triple-transgenic AE[UAS]/hs-GAL4/UAS-srp larvae. Under these conditions, one would expect GAL4 expression to produce two simultaneous effects. The first is direct activation of the Fbp1 enhancer resulting from the binding of GAL4 to the UAS site in the AE[UAS] construct, as observed with the GAL4 ${ }^{\mathrm{daG} 32}$ driver (Fig. 2). The second is overexpression of the UAS-srp transgene, also resulting in activation of the Fbpl enhancer, as demonstrated above. Following heat shocks during the second and third larval instars, simultaneous activation of the AE[UAS] transgene by both GAL4 and GATAb resulted in lac $Z$ induction in the fat body, salivary glands, and proventriculus (data not shown). In addition, quantitative measurements indicated that a high level of lac $Z$ expression was obtained throughout this period (Fig. 7C). It should be stressed that this high level of $l a c Z$ induction in the second and early third instars required the simultaneous overexpression of GAL4 and GATAb. It was not obtained for either the AE[UAS] transgene upon activation by GAL4 alone (Fig. 2B) or the AE transgene upon activation by overexpressed GATAb alone (Fig. 7B). Together, these results strongly suggested that both GATAb and the EcR/USP heterodimer are limiting factors in the activation of the Fbp1 enhancer.

\section{DISCUSSION}

Tissue- and time-specific factors modulate the primary ecdysone response. Understanding the mechanisms that control the tissue-specific expression of ecdysone response genes represents a major challenge, given the fact that ecdysone exercises its signaling activity on virtually all larval and imaginal tissues at pupariation. The $E c R$ gene encodes three different isoforms, EcR-A, B1, and B2, that differ in the N-terminal part. Differential expression of EcR isoforms in larval and imaginal tissues during development and analysis of EcR isoform-specific mutants have led to the proposal that the tissue specificity of ecdysone target genes could rely in part on selective activation by a given EcR isoform heterodimerized with USP (8, 42, 44). However, a number of genes are differentially induced in response to ecdysone in various larval tissues where only the EcR-B1 isoform predominates. These genes include, for example, the Fbp1 gene in the fat body and the $s g s$ genes in the salivary glands (25). Hence, it is clear that differential expression of EcR isoforms is not sufficient to specify the activation of a given ecdysone response gene in a given tissue.

Lehmann and Korge (26) showed that the transcription factor Forkhead specifies the ecdysone responsiveness of the Sgs4 gene in the salivary glands, providing the first molecular evidence that a primary ecdysone response is controlled not only by the EcR/USP heterodimer but also by other tissue-specific transcription factors. Our study adds strong support to this model. The replacement of the EcR/USP target site with a UAS site in the Fbpl enhancer allowed us to functionally substitute the yeast transcription factor GAL4 for the ecdysone receptor. Yet, in a genetic context where GAL4 was ubiquitously expressed, the modified $F b p 1$ enhancer still directed transcription specifically in the fat body. In addition, the activity of this modified enhancer was restricted to the third larval instar. These results indicate that one or several transcription factors modulate, both spatially and temporally, the GAL4driven activation of the $F b p 1$ enhancer and strongly suggest that the same factors play this specific role in a natural context where the ecdysone receptor binds to the Fbpl enhancer. Because GAL4 and the ecdysone receptor are completely unrelated, it is very unlikely that these modulating factors are direct partners of EcR/USP. This leads us to conclude that the genetic response to ecdysone is controlled not only by the EcR/ USP heterodimer and the concentration of its ligand but also by other tissue- and time-specific transcription factors targeted to sequences flanking EcR/USP binding sites.

We have identified GATAb as belonging to this class of factors. The Fbpl enhancer encompasses three distinct GATAb binding sites, but only GBS1 is functionally required in our assay. The fact that the tandemly repeated GATAb binding sites GBS2 and GBS3 are not essential is at odds with the observation that pairs of GATA sites arranged in tandem have been found to be involved in the regulation of mammalian genes in hematopoietic cells (35) and Drosophila yolk protein genes in ovaries (28). Nevertheless, the possibility that GBS2 and GBS3 play a functional role in the proper expression of the endogenous Fbpl gene is still open to question.

During the third larval instar, GATAb is expressed not only in the fat body but also in the gonads, lymph glands, and 
70h

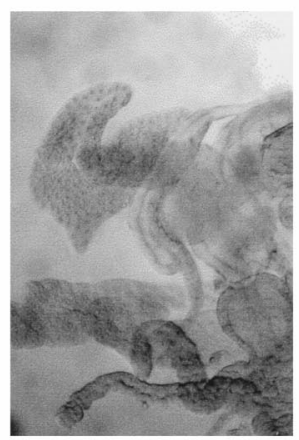

A

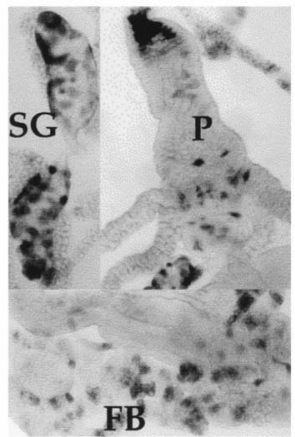

88h
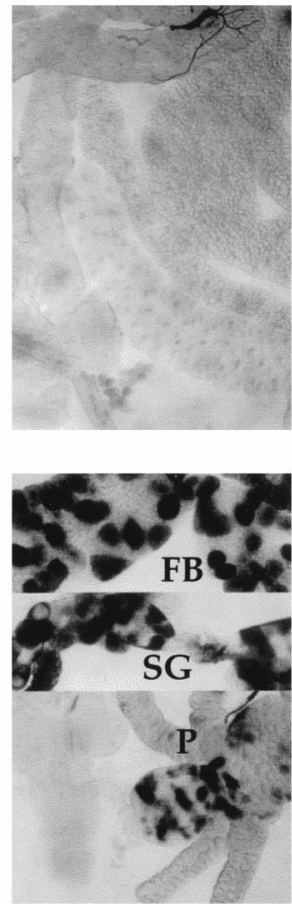

118h

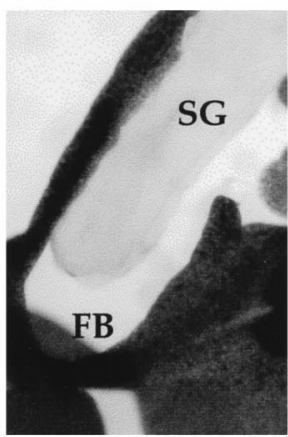

$-H S$

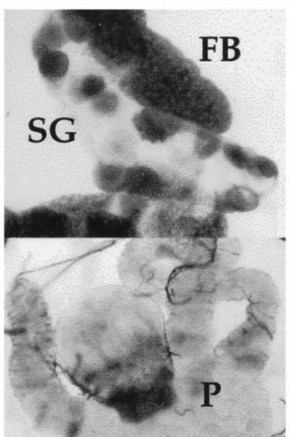

$+\mathrm{HS}$
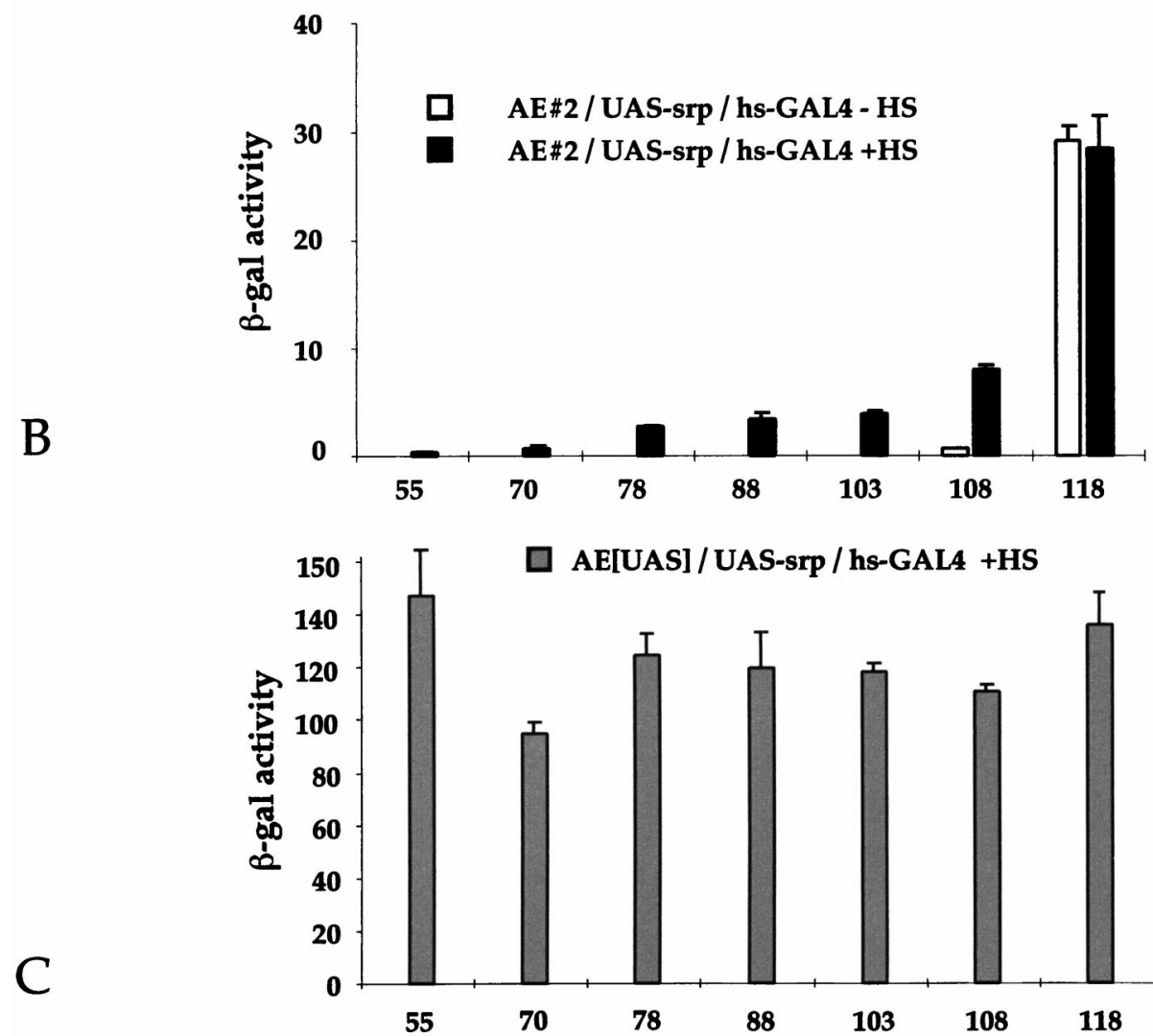

FIG. 7. GATAb is involved in both the timing and tissue specificity of Fbp1 gene expression. (A) Larvae heterozygous for the AE-lacZ, hs-GAL4, and UAS-srp transgenes were heat shocked for $1 \mathrm{~h}$ at $37^{\circ} \mathrm{C}$ at various developmental stages and allowed to recover for $7 \mathrm{~h}$ at $25^{\circ} \mathrm{C}$ (bottom; +HS). Immunostaining of heat-shocked larvae indicated that the Srp protein was ubiquitously overexpressed (data not shown). Tissues were dissected and histochemically stained for $\beta$-galactosidase activity. The times indicated correspond to the dissection of larvae. The images at the top show histochemical staining of control larvae that were not heat shocked $(-\mathrm{HS})$. Abbreviations: P, proventiculus; FB, fat body; SG, salivary glands. (B) $\beta$-Galactosidase ( $\beta$-gal) activity in extracts from AE/hs-GAL4/UAS-srp larvae treated as described for panel A with (black bars) or without (open bars) heat shock treatment. The times indicated at the bottom in hours correspond to times after egg laying at which larvae were dissected. (C) $\beta$-Galactosidase activity in extracts from heat-shocked AE[UAS]/hs-GAL4/UAS-srp larvae treated as described for panel A. 
anterior midgut. This is in contrast with the restriction of Fbp1 expression to the fat body and rules out the hypothesis that Fbp1 tissue specificity is simply determined by GATAb transactivation. However, ubiquitous overexpression of GATAb in second- and third-instar larvae leads to ectopic expression of the Fbpl-lacZ transgene in the salivary glands and the proventriculus, indicating that a proper expression pattern of this transcription factor is required to achieve the correct tissue specificity of Fbp1 expression. The absence of ectopic induction of Fbp1-lacZ in other tissues suggests that the presence of negative regulators and/or the lack of other transactivators prevented the switching on of the Fbp1 enhancer by GATAb in these tissues. Interestingly, the functional importance of GBS1 in vivo correlates with the efficient formation of GATAb-containing complexes $\mathrm{a}$ and $\mathrm{b}$ in vitro. By comparison, the formation of these retarded complexes is much less efficient with GBS3 and not detectable with GBS2. This result suggests that the factors involved in the formation of GATAb-containing complexes $\mathrm{a}$ and $\mathrm{b}$ may be the regulators whose activity is necessary, in addition to that of GATAb and EcR/USP, for activation of the Fbp1 enhancer. As we have shown that these additional complexes do not correspond to multimers of GATAb, two nonexclusive hypotheses can be put forward to explain their formation. One is that they result from the preferential binding of distinct GATAb isoforms to GBS1. Although a single GATAb mRNA species was revealed by Northern blot analysis in third-instar larvae (1), the GATAb protein is detected as a double band in a Western blot assay, indicating that different GATAb isoforms may exist in the fat body. A second is that cofactors associate with GATAb to form complexes $a$ and $b$ that preferentially bind to GBS1. Yet, overexpression of the GATAb cDNA does not result in the reinforcement of complexes a and b, suggesting that the quantity of the factors responsible for their formation is limiting in the fat body. Multiple interactions between GATA factors and protein partners have been described recently $(17,20,36,45,48$, 49). It is thus tempting to speculate that protein-protein interactions with partners modulate the fat body-specific activity of GATAb.

Dual requirement of GATAb and EcR/USP for specific activation of the $\boldsymbol{F b p} \boldsymbol{1}$ enhancer. Disruption of either GATAb binding site GBS1 or the EcR/USP binding site result in complete inactivation of the $F b p 1$ enhancer, indicating that both GATAb and the ecdysone receptor are strictly required for its activity. What are the contributions of both of these factors to the induction of $F b p 1$ expression?

Fbp1 is only induced at the end of the third larval instar. In contrast, GATAb is expressed at a constant level in the fat body from the mid-second larval instar to pupariation. Thus, it is clear that the precise transcription timing of $F b p 1$ is not controlled solely by GATAb. Consistently during GATAb overexpression, the premature activation of the AE transgene is gradual and remains limited during the second larval instar and the first half of the third larval instar (Fig. 7). Thus, although this result provides additional evidence that GATAb is involved in Fbpl transactivation, it also shows that other transcription factors are required at the end of the third larval instar for maximal induction of $F b p 1$. A number of findings demonstrate that one of these factors is the ecdysone receptor which is activated by its ligand only during the second part of the third larval instar. First, the disruption of the EcR/USP binding site in the Fbpl enhancer results in its complete inactivation. Second, in ecdysone-deficient mutant strains, induction of the Fbpl gene is abolished and this induction can be restored by feeding larvae with exogenous ecdysteroids (24). Third, we show here that the AE[UAS] construct, in which the
EcR/USP target site has been replaced with a GAL4 binding site, is prematurely induced at the beginning of the third larval instar upon activation by constantly expressed GAL4.

However, our results indicate clearly that the active EcR/ USP receptor is not the only factor involved in the switching on of Fbp1. The premature induction of AE[UAS] by GAL4 also remains gradual during the third larval instar. This distinctly suggests that, in addition to GATAb and EcR/USP, other transcription factors whose activity increases gradually through the third larval instar are involved in the fine tuning of the timing of $F b p 1$ expression. Yet, upon simultaneous overexpression of GATAb and GAL4, the AE[UAS] transgene becomes expressed at a constant level from the mid-second instar until puparium formation. These data have two implications. First, they indicate that the requirement for these other transcription factors, whose identity remains to be determined, can be bypassed under nonphysiological conditions. Second, they add further evidence that GATAb and EcR/USP act together to turn on the Fbpl enhancer, the ecdysone receptor being the ultimate timer for its induction.

Physical interactions between the vertebrate GATA-1 factor and nuclear receptors for glucocorticoids (13) and estrogen (9) have been described. The close proximity of the DNA target sites for GATAb and the EcR/USP ecdysone receptor in the Fbp1 enhancer makes it feasible that GATAb and EcR/USP establish similar contacts. However, the fat body-specific expression of the AE[UAS] transgene in a GAL4 genetic context suggests that protein-protein interactions between the ecdysone receptor and GATAb are not required for the achievement of tissue specificity.

\section{ACKNOWLEDGMENTS}

We are grateful to M. D. Brennan and J. Hu for the gift of the \#Srp antibody, to P. Ramain for the gift of the \#2B8 antibody, and to R. Reuter and K.-P. Rehorn for the gift of the srp cDNA and the UAS-srp Drosophila line. We thank R. Reuter, K.-P. Rehorn, Y. Engström, and U.-M. Petersen for helpful discussions and for sharing information during the course of this work. We thank F. Schweisguth and A. Kropfinger for critical reading of the manuscript and M. Sémériva for expert advice on pericardial cells and lymph glands in dissections of fat bodies.

V. Brodu is a predoctoral fellow of the Ministère de la Recherche et de l'Enseignement. This work was supported by grants to J.-A. Lepesant from the Association pour la Recherche contre le Cancer (grant 6294), the Ligue Nationale Contre le Cancer, and the Centre National de la Recherche Scientifique.

\section{REFERENCES}

1. Abel, T., A. M. Michelson, and T. Maniatis. 1993. A Drosophila GATA family member that binds to Adh regulatory sequences is expressed in the developing fat body. Development 119:623-633.

2. Andres, A. J., J. C. Fletcher, F. D. Karim, and C. S. Thummel. 1993. Molecular analysis of the initiation of insect metamorphosis: a comparative study of Drosophila ecdysteroid-regulated transcription. Dev. Biol. 160:388404.

3. Andres, A. J., and C. S. Thummel. 1992. Hormones, Puffs and flies: the molecular control of metamorphosis by ecdysone. Trends Genet. 8:132-138. 3a.Antoniewski, C. Unpublished data.

4. Antoniewski, C., M. Laval, A. Dahan, and J. A. Lepesant. 1994. The ecdysone-response enhancer of the Fbp1 gene of Drosophila melanogaster is a direct target for the EcR/USP nuclear receptor. Mol. Cell. Biol. 14:44654474 .

5. Antoniewski, C., B. Mugat, F. Delbac, and J.-A. Lepesant. 1996. Direct repeats bind the EcR/USP receptor and mediate ecdysteroid responses in Drosophila melanogaster. Mol. Cell. Biol. 16:2977-2986.

6. Ashburner, M. 1989. Drosophila: a laboratory handbook, p. 1331. Cold Spring Harbor Laboratory Press, Cold Spring Harbor, N.Y.

7. Barnett, S. W., K. Flynn, M. K. Webster, and S. K. Beckendorf. 1990. Noncoordinate expression of Drosophila glue genes: sgs 4 is expressed at many stages and in two different tissues. Dev. Biol. 140:362-373.

8. Bender, M., F. B. Imam, W. S. Talbot, B. Ganetzky, and D. S. Hogness. 1997. 
Drosophila ecdysone receptor mutations reveal functional differences among receptor isoforms. Cell 91:777-788.

9. Blobel, G. A., C. A. Sieff, and S. H. Orkin. 1995. Ligand-dependent repression of the erythroid transcription factor GATA-1 by the estrogen receptor. Mol. Cell. Biol. 15:3147-3153.

10. Brand, A. H., and N. Perrimon. 1993. Targeted gene expression as a means of altering cell fates and generating dominant phenotypes. Development 118:401-415

11. Broadus, J., J. R. McCabe, B. Endrizzi, C. S. Thummel, and C. T. Woodard. 1999. The Drosophila beta FTZ-F1 orphan nuclear receptor provides competence for stage-specific responses to the steroid hormone ecdysone. Mol. Cell 3:143-149.

11a.Brodu, V., and C. Antoniewski. Unpublished data.

12. Burmester, T., C. Antoniewski, and J.-A. Lepesant. Ecdysone-regulation of synthesis and processing of fat body protein 1, the larval serum protein receptor of Drosophila melanogaster. Eur. J. Biochem., in press.

13. Chang, T. J., B. M. Scher, S. Waxman, and W. Scher. 1993. Inhibition of mouse GATA-1 function by the glucocorticoid receptor: possible mechanism of steroid inhibition of erythroleukemia cell differentiation. Mol. Endocrinol. 7:528-542.

14. Coschigano, K. T., and P. C. Wensink. 1993. Sex-specific transcriptional regulation by the male and female doublesex proteins of Drosophila. Genes Dev. 7:42-54

15. Crossley, M., M. Merika, and S. H. Orkin. 1995. Self-association of the erythroid transcription factor GATA-1 mediated by its zinc finger domains. Mol. Cell. Biol. 15:2448-2456.

16. Desplan, C., J. Theis, and P. H. O'Farrell. 1985. The drosophila developmental gene, engrailed, encodes a sequence-specific DNA binding activity. Nature 318:630-635.

17. Durocher, D., F. Charron, R. Warren, R. J. Schwartz, and M. Nemer. 1997. The cardiac transcription factors Nkx2-5 and GATA-4 are mutual cofactors. EMBO J. 16:5687-5696.

18. Evans, T., G. Felsenfeld, and M. Reitman. 1990. Control of globin gene transcription. Annu. Rev. Cell Biol. 6:95-124.

19. Glass, C. K., D. W. Rose, and M. G. Rosenfeld. 1997. Nuclear receptor coactivators. Curr. Op. Cell Biol. 9:222-232.

20. Haenlin, M., Y. Cubadda, F. Blondeau, P. Heitzler, Y. Lutz, P. Simpson, and P. Ramain. 1997. Transcriptional activity of Pannier is regulated negatively by heterodimerization of the GATA DNA-binding domain with a cofactor encoded by the $u$-shaped gene of Drosophila. Genes Dev. 11:3096-3108.

21. Hu, J. 1995. The role of DNA/protein interactions in transcription from the larval promoter of the D. Affinidisjuncta alcohol dehydrogenase gene. Ph.D. thesis. University of Louisville, Louisville, Ky.

22. Koelle, M. R., W. S. Talbot, W. A. Segraves, M. T. Bender, P. Cherbas, and D. S. Hogness. 1991. The drosophila $E c R$ gene encodes an ecdysone receptor, a new member of the steroid receptor superfamily. Cell 67:59-77.

23. Lam, G. T., C. Jiang, and C. S. Thummel. 1997. Coordination of larval and prepupal gene expression by the DHR3 orphan receptor during Drosophila metamorphosis. Development 124:1757-1769.

24. Laval, M., F. Pourrain, J. Deutsch, and J. A. Lepesant. 1993. In vivo functional characterization of an ecdysone-response enhancer in the proximal upstream region of the Fbp1 gene of D. melanogaster. Mech. Dev. 44:123138.

25. Lehmann, M. 1996. Drosophila Sgs genes: stage and tissue specificity of hormone responsiveness. Bioessays 18:47-54.

26. Lehmann, M., and G. Korge. 1996. The fork head product directly specifies the tissue-specific hormone responsiveness of the Drosophila Sgs-4 gene. EMBO J. 15:4825-4834.

27. Lepesant, J. A., F. Maschat, J. Kejzlarovà-Lepesant, H. Benes, and C. Yanicostas. 1986. Developmental and ecdysteroid regulation of gene expression in the larval fat body of Drosophila melanogaster. Arch. Insect Biochem. Physiol. s1:133-141.

28. Lossky, M., and P. C. Wensink. 1995. Regulation of Drosophila yolk protein genes by an ovary-specific GATA factor. Mol. Cell. Biol. 15:6943-6952.

29. Lucas, P. C., and D. K. Granner. 1992. Hormone response domains in gene transcription. Annu. Rev. Biochem. 61:1131-1173.

30. Mangelsdorf, D. J., C. Thummel, M. Beato, P. Herrlich, G. Schutz, K. Umesono, B. Blumberg, P. Kastner, M. Mark, P. Chambon, et al. 1995. The nuclear receptor superfamily: the second decade. Cell 83:835-839.

31. Maschat, F., M. L. Dubertret, P. Thérond, J. M. Claverie, and J. A. Lepe- sant. 1990. Structure of the ecdysone-inducible $P 1$ gene of Drosophila melanogaster. J. Mol. Biol. 214:359-372.

32. Merika, M., and S. H. Orkin. 1993. DNA-binding specificity of GATA family transcription factors. Mol. Cell. Biol. 13:3999-4010.

33. Moore, L. A., H. T. Broihier, M. Van Doren, and R. Lehmann. 1998. Gonadal mesoderm and fat body initially follow a common developmental path in drosophila. Development 125:837-844.

34. Noselli, S., and A. Vincent. 1992. The Drosophila melanogaster ribosomal protein L17A-encoding gene. Gene 118:273-278.

35. Orkin, S. H. 1992. GATA-binding transcription factors in hematopoietic cells. Blood 80:575-581.

36. Osada, H., G. Grutz, H. Axelson, A. Forster, and T. H. Rabbitts. 1995. Association of erythroid transcription factors: complexes involving the LIM protein RBTN2 and the zinc-finger protein GATA1. Proc. Natl. Acad. Sci. USA 92:9585-9589.

37. Ramain, P., P. Heitzler, M. Haenlin, and P. Simpson. 1993. Pannier, a negative regulator of achaete and scute in Drosophila, encodes a zinc finger protein with homology to the vertebrate transcription factor GATA-1. Development 119:1277-1291.

38. Rehorn, K. P., H. Thelen, A. M. Michelson, and R. Reuter. 1996. A molecular aspect of hematopoiesis and endoderm development common to vertebrates and Drosophila. Development 122:4023-4031.

39. Riechmann, V., K. P. Rehorn, R. Reuter, and M. Leptin. 1998. The genetic control of the distinction between fat body and gonadal mesoderm in Drosophila. Development 125:713-723.

40. Rubin, G. M., and A. C. Spradling. 1982. Genetic transformation of Drosophila with transposable element vectors. Science 218:348-353.

41. Sam, S., W. Leise, and D. K. Hoshizaki. 1996. The serpent gene is necessary for progression through the early stages of fat-body development. Mech. Dev. 60:197-205.

42. Schubiger, M., A. A. Wade, G. E. Carney, J. W. Truman, and M. Bender. 1998. Drosophila EcR-B ecdysone receptor isoforms are required for larval molting and for neuron remodeling during metamorphosis. Development 125:2053-2062.

43. Simon, J. A., and J. T. Lis. 1987. A germline transformation analysis reveals flexibility in the organization of heat shock consensus elements. Nucleic Acids Res. 15:2971-2988

44. Talbot, W. S., E. A. Swyryd, and D. S. Hogness. 1993. Drosophila tissues with different metamorphic responses to ecdysone express different ecdysone receptor isoforms. Cell 73:1323-1337.

45. Tevosian, S. G., A. E. Deconinck, A. B. Cantor, H. I. Rieff, Y. Fujiwara, G. Corfas, and S. H. Orkin. 1999. FOG-2: a novel GATA-family cofactor related to multitype zinc-finger proteins Friend of GATA-1 and U-shaped. Proc. Natl. Acad. Sci. USA 96:950-955.

46. Thomas, H. E., H. G. Stunnenberg, and A. F. Stewart. 1993. Heterodimerization of the Drosophila ecdysone receptor with retinoid $\mathrm{X}$ receptor and ultraspiracle. Nature 362:471-475.

47. Thummel, C. S. 1996 . Flies on steroids-drosophila metamorphosis and the mechanisms of steroid hormone action. Trends Genet. 12:306-310.

48. Tsang, A. P., J. E. Visvader, C. A. Turner, Y. Fujiwara, C. Yu, M. J. Weiss, M. Crossley, and S. H. Orkin. 1997. FOG, a multitype zinc finger protein, acts as a cofactor for transcription factor GATA-1 in erythroid and megakaryocytic differentiation. Cell 90:109-119.

49. Wadman, I. A., H. Osada, G. G. Grutz, A. D. Agulnick, H. Westphal, A. Forster, and T. H. Rabbitts. 1997. The LIM-only protein Lmo2 is a bridging molecule assembling an erythroid, DNA-binding complex which includes the TAL1, E47, GATA-1 and Ldb1/NLI proteins. EMBO J. 16:3145-3157.

50. White, K. P., P. Hurban, T. Watanabe, and D. S. Hogness. 1997. Coordination of Drosophila metamorphosis by two ecdysone-induced nuclear receptors. Science 276:114-117.

51. Wodarz, A., U. Hinz, M. Engelbert, and E. Knust. 1995. Expression of crumbs confers apical character on plasma membrane domains of ectodermal epithelia of Drosophila. Cell 82:67-76.

52. Yao, T. P., B. M. Forman, Z. Jiang, L. Cherbas, J.-D. Chen, M. McKeown, P. Cherbas, and R. M. Evans. 1993. Functional ecdysone receptor is the product of EcR and Ultraspiracle genes. Nature 336:476-479.

53. Young, P. E., T. C. Pesacreta, and D. P. Kiehart. 1991. Dynamic changes in the distribution of cytoplasmic myosin during Drosophila embryogenesis. Development 111:1-14 